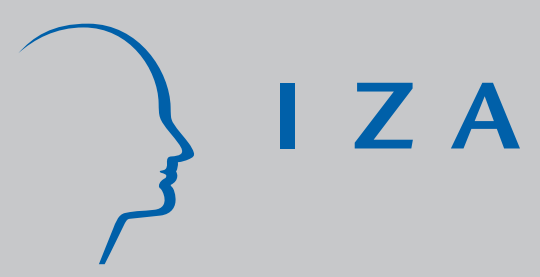

IZA DP No. 423

\title{
Transfer Fee Regulations in European Football
}

\section{Eberhard Feess}

Gerd Muehl heusser

February 2002 


\title{
Transfer Fee Regulations in European Football
}

\author{
Eberhard Feess \\ University of Aachen, Department of Economics \\ Gerd Muehlheusser \\ University of Bonn, Department of Economics \\ and IZA, Bonn
}

Discussion Paper No. 423
February 2002

\author{
IZA \\ P.O. Box 7240 \\ D-53072 Bonn \\ Germany \\ Tel.: +49-228-3894-0 \\ Fax: +49-228-3894-210 \\ Email: iza@iza.org
}

This Discussion Paper is issued within the framework of IZA's research area Mobility and Flexibility of Labor. Any opinions expressed here are those of the author(s) and not those of the institute. Research disseminated by IZA may include views on policy, but the institute itself takes no institutional policy positions.

The Institute for the Study of Labor (IZA) in Bonn is a local and virtual international research center and a place of communication between science, politics and business. IZA is an independent, nonprofit limited liability company (Gesellschaft mit beschränkter Haftung) supported by the Deutsche Post AG. The center is associated with the University of Bonn and offers a stimulating research environment through its research networks, research support, and visitors and doctoral programs. IZA engages in (i) original and internationally competitive research in all fields of labor economics, (ii) development of policy concepts, and (iii) dissemination of research results and concepts to the interested public. The current research program deals with (1) mobility and flexibility of labor, (2) internationalization of labor markets, (3) the welfare state and labor markets, (4) labor markets in transition countries, (5) the future of labor, (6) evaluation of labor market policies and projects and (7) general labor economics.

IZA Discussion Papers often represent preliminary work and are circulated to encourage discussion. Citation of such a paper should account for its provisional character. A revised version may be available on the IZA website (www.iza.org) or directly from the author. 
IZA Discussion Paper No. 423

February 2002

\title{
ABSTRACT
}

\section{Transfer Fee Regulations in European Football*}

We analyze the impact of three different transfer fee systems on payoffs, contract lengths, training and effort incentives in European football. The different regimes, being used until 1995 ("Pre-Bosman" or P), currently in use ("Bosman" or B), and recently approved ("Monti" or $M$ ) differ with respect to the transfer fee an initial club must accept in case of a transfer depending on whether a player has a valid contract or not. We show that the different systems differ only with respect to the contract length if the contract which maximizes the expected joint surplus of the initial club and the player is feasible under each system. Otherwise, regime $P$ is strictly dominated by regime $B$ in terms of expected social welfare. Regime $M$ leads to higher effort but lower incentives to invest in training compared to system $B$.

JEL Classification: J41, K12, L83

Keywords: Labor contracts, Bosman judgement, transfer fees, breach of contract, investment incentives, general skills, externalities

\author{
Gerd Mühlheußer \\ University of Bonn \\ Department of Economics \\ Adenauerallee 24-42 \\ 53113 Bonn \\ Germany \\ Tel.: +49 228733918 \\ Fax: +49 228739221 \\ gerd.muehlheusser@wiwi.uni-bonn.de
}

\footnotetext{
* The second author gratefully acknowledges financial support from the German Academic Exchange Service (DAAD) during his stay at the London School of Economics, where part of this research was conducted, and from the Deutsche Forschungsgemeinschaft (DFG, Graduiertenkolleg "Quantitative Economics" at the University of Bonn). We are grateful to Heski Bar-Isaac, Anke Kessler, Bentley MacLeod, Martin Nell, Horst Raff, Andreas Roider, Wendelin Schnedler, Urs Schweizer, and Frank Staehler for helpful comments.
} 


\section{Introduction}

Legal situation and motivation The issue of transfer fees in European football has attracted considerable attention in recent years. In the famous "Bosman Case", the European Court of Justice ruled in December 1995 that the commonly used transfer system was not in accordance with article 39 of the Treaty of Rome, because it was judged to hamper the mobility of professionals. ${ }^{1}$ Since the verdict, clubs are no longer entitled to receive transfer fees for out-of-contract players. ${ }^{2}$ Before the judgement, a new club had to pay a fee even if a player's contract had expired. These transfer fees were fixed by the National Football Associations and were increasing in the strength of the new club, and decreasing in the strength of the old club. One alleged aim of this system was to redistribute income to maintain competitive balance and enhance the incentives to invest in training of young talents.

While the Bosman judgement only concerned transfer fees for expired contracts, the European Commission (in particular Commissioner Monti) recently pushed the issue further by also challenging transfer rules for valid contracts. According to a compromise between the Commission, FIFA and UEFA, reached in March 2001, a player can leave his current club without its approval on paying a fee for breach of contract and, depending on the age the player, a fee for compensation of educational expenses. This is in sharp contrast to the former rule, since the club could impede the transfer if it did not want to accept the fees offered by other clubs. Under the new rule, the sum of both fees for breach of contract will usually be substantially lower than the freely negotiable transfer fee. Another important feature of the compromise is to restrict the range of admissible contract length from one to five years. As had already been the case after the Bosman judgement, complaints by many members of the football community were numerous and vociferous, and it was argued that no one would be willing to train young talents under the new legislation.

\footnotetext{
${ }^{1}$ See Court of Justice of the European Communities, Case C-415/93.

${ }^{2}$ Another implication of the verdict was that the number of players from European countries was no longer restricted.
} 
Framework and main results The present paper compares the systems being used until 1995 (labelled Pre-Bosman system or P), currently in use ("Bosman" or B) and recently approved ("Monti" or $M$ ). In particular, we analyze the impact of relaxing the transfer rules on the allocation of players, the investments in training of talents, the incentives of players to exert effort, and the distribution of surplus among clubs and players. We develop a model in which talents have to be trained in order to become professionals. Successful training creates a general skill which may be used in other clubs as well. Thus, investment in training creates a positive externality on other clubs. After becoming professionals ("players"), they exert effort which determines their performance in the current club and the probability of a shock, which would make them more productive in another club. If the shock occurs, renegotiation between the clubs and the player occurs. Together with the contract length, transfer rules determine the outcome of this renegotiation game. Since the outcome of the renegotiation game will be anticipated ex ante, it also determines the structure of the initial contract in a subgame perfect equilibrium.

The main findings of our paper can be explained as follows: When signing the initial contract, the talent and his club choose the contract length to maximize expected joint surplus. Thereby, they face a fundamental trade-off. On the one hand, the shorter the initial contract, the higher the player's stake in the renegotiation game, because he benefits from being out of contract. This induces him to exert higher effort, since this increases the probability that the shock occurs. Hence, the shorter the initial contract, the higher the player's effort. For instance, recently Bayern Munich's top player Stefan Effenberg has publicly declared that he intends to increase his effort since he can leave for free when his contract expires. On the other hand, short term contracts do not only increase the player's stake in the renegotiation game, but also the new club's stake, since it is less costly to buy an out-of-contract player. Ceteris paribus, the higher the new club's stake in the renegotiation game, the lower the expected surplus of the talent and his initial club.

When designing the initial contract, the initial club and the player are trying to balance these countervailing effects at the margin. Thereby, they take into account that the distribution of payoffs in the renegotiation game do not only depend on the contract length but also on the transfer system. For instance, if the contract length is the same 
under regimes $B$ and $M$, then the player's and the new club's stakes will be higher under regime $M$. Because the trade-off described above is essentially the same under all systems, the optimal contract length is higher under regime $M$. For similar reasons, they prefer shorter contracts under regime $P$. The crucial effect of transfer systems is to determine the feasible set of payoffs in the renegotiation game which can be implemented ex-ante through variations in the contract length. The feasible set is maximal under the current system $B$, since the player's stake is maximal without a valid contract, and minimal with contract. We show that if the desired payoff distribution can be achieved under all regimes, then the regimes differ only with respect to the equilibrium contract length, but not with respect to investment and effort incentives.

However, the desired payoff distribution may not be feasible under either regime $P$ or regime $M$. If the transfer fee for expired contracts under $P$ is too high, then any initial contract will inevitably implement too low a payoff for the player. Then, system $P$ is strictly inferior to system $B$. Under system $M$, the player's stake may always be higher than the stake induced by the contract which maximizes the player's and the initial club's joint surplus. Under these circumstances, regime $M$ leads to higher effort but to lower investments compared to system $B$, so that the overall effect on social welfare is ambiguous.

Relation to the literature There are only a few contributions analyzing the impact of transfer fee systems in professional sports. That transfer fees do not distort the allocation of players due to the Coase Theorem was pointed out by Demsetz (1972). Recently, this has been emphasized by Kesenne (1999), and is also exploited in our paper. ? analyzes the short term effects of the Bosman judgement and argues that players and new clubs benefit from the judgement. This also holds in our model if one treats the initial contracts as given. Using a dynamic investment model, Antonioni and Cubbin (2000) analyze the effect of the Bosman judgement and emphasize the possibility to write long term contracts to protect investments. Other articles focus on the effect of transfer systems on competitive balance within a league, an issue not explicitly discussed in this paper. ${ }^{3}$

\footnotetext{
${ }^{3}$ See Quirk and Fort (1997, Ch.6) for US professional leagues and Szymanski and Kuypers (1999, Ch.3) for the English Premier League.
} 
Finally, Feess and Muehlheusser (2000) compare the Commission's Suggestion with the current practice in a model in which different contract lengths are explained as a signaling device on the player's privately known future performance. However, they do not analyze the trade-off considered in this paper.

From a more theoretical point of view, our analysis is related to many papers analyzing the incentives of firms to invest in general training of workers. Acemoglu (1997) also derives underinvestment results in a model with innovation, in which part of the benefits from training are captured by future employers. Acemoglu and Pischke (1999b) analyze investment incentives for training which provides general skills in a world of imperfect labor markets. ${ }^{4}$

Furthermore, our model is related to the literature on fees for breach of contract. Spier and Whinston (1995) analyze an incomplete contracting model with specific investments in which the buyer ex-ante signs a contract with a seller, but can ex-post either trade with the seller or with an entrant. If a potential entrant gets a positive share of the surplus, then the incumbent firm and the buyer have incentives to extract rents by stipulating excessive fees for breach in the initial contract. The effect is comparable to our result that the player and the initial club have an incentive to reduce the new club's stake by agreeing on long-term contracts. ? show that the seller's investment incentives are the lower, the higher the complementarity between specific and general investment.

Our paper is most closely related to Burguet, Caminal, and Matutes (2001) who enquire why some workers have contracts with high buy-out fees while others have not. They stress the role of the observability of a worker's performance: If it is publicly observable (as we would presume in the context of professional sports), then again the role of fees is to extract rents from future employers, while there is no role for fees when the performance is private information to the worker. The basic structure of our bargaining game introduced in section 3 closely follows their approach.

The remainder of the paper is organized as follows: In section 2, the model is presented. Section 3 formalizes the different transfer systems and the renegotiation game. The main results are derived in section 4 . Section 5 discusses our main assumptions and

\footnotetext{
${ }^{4}$ For a survey of the literature on training in imperfect labor markets, see Acemoglu and Pischke (1999a).
} 
derives some ideas for further research.

\section{The model}

We consider two ex-ante identical clubs indexed $k=1,2$ competing for a single talent. At date -2 , clubs compete for the talent by simultaneously suggesting contracts $\Omega_{k}=\left(I_{k}\right.$, $\left.t_{k}, W_{k}\right)$. These contracts specify an investment level $I_{k}$ for the talent's training, a contract length $0 \leq t_{k} \leq 1$, and an up-front payment $W_{k}$ in case the talent becomes a player. The talent signs the contract that maximizes his expected utility $U$. When both clubs make identical offers, then each club is chosen with probability 0.5 . The club chosen by the talent is called "initial club" and labelled club $i$.

At date -1 , club $i$ invests $I$ as specified in the contract, and the talent becomes a player with probability $p(I)$. We assume $p^{\prime}>0, p^{\prime \prime}<0, \lim _{I \rightarrow \infty} p^{\prime}=0$ and $\lim _{I \rightarrow 0}$ $p^{\prime}=\infty$. Training costs are simply given by $C(I)=I$. Our assumptions that the wage $W_{k}$ is paid up-front and that the investment is contractible are discussed in section 5 .

If the talent becomes a player, his career starts at date 0 and ends at date 1 . Before playing for his initial club, at date 0 , the player chooses effort $e \in[\underline{e}, \bar{e}]$ which is assumed to be observable but non-verifiable. The player's effort choice has two impacts: up to a certain date $\underline{t}$, it determines his productivity in the initial club which is simply $e$. Furthermore, it determines the probability $g(e)$ of a productivity shock at date $\underline{t}$, where $g(\underline{e})=0, g^{\prime}>0, g^{\prime \prime}<0$, and $g^{\prime \prime \prime}<0 \forall e>\underline{e} .^{5} \quad$ Effort costs are zero up to $\underline{e}>0$, while effort levels $e>\underline{e}$ involve effort $\operatorname{costs} c(e)$ where $c^{\prime}>0, c^{\prime \prime}>0$ and $c^{\prime \prime \prime} \geq 0$. We have in mind that there is no incentive problem in inducing $\underline{e}$ which might be justified in several ways: First, the player may be ashamed when performing too poorly. Second, he might have to perform well to get on the team at all. Finally, one could assume that $e$ is contractible up to $\underline{e}$.

If the shock occurs, it leads to productivity $h>\bar{e}$ in the other club ("club $h$ "). Since exerting effort determines the probability of the shock, the player's effort incentive is the higher the higher his net benefit in case a shock occurs. ${ }^{6}$ Following the logic of the

\footnotetext{
${ }^{5}$ We have also considered a continuous version where the shock can occur at any time between dates dates 0 and 1 . This increases the complexity of the model without leading to additional insights.

${ }^{6}$ Additionally, one could assume that his effort also increases his future productivity in his initial club,
} 
Coase theorem, the player will always join club $h$ at date $\underline{t}$ if the shock occurs. Since the transfer would increase the surplus per unit of time by $h-\underline{e}>0$, all participants can be better off by agreeing on that transfer. Depending on the legal situation and the length of the initial contract, this might lead to renegotiation (the details of the renegotiation game are spelled out in section 3). If the shock does not occur, then the player stays in his initial club and exerts effort $\underline{e}$, because there would be no gain in choosing a higher effort level, while costs $c(e)$ are strictly positive for $e>\underline{e}$. Summarizing, the sequence of events is as shown in Figure 1.

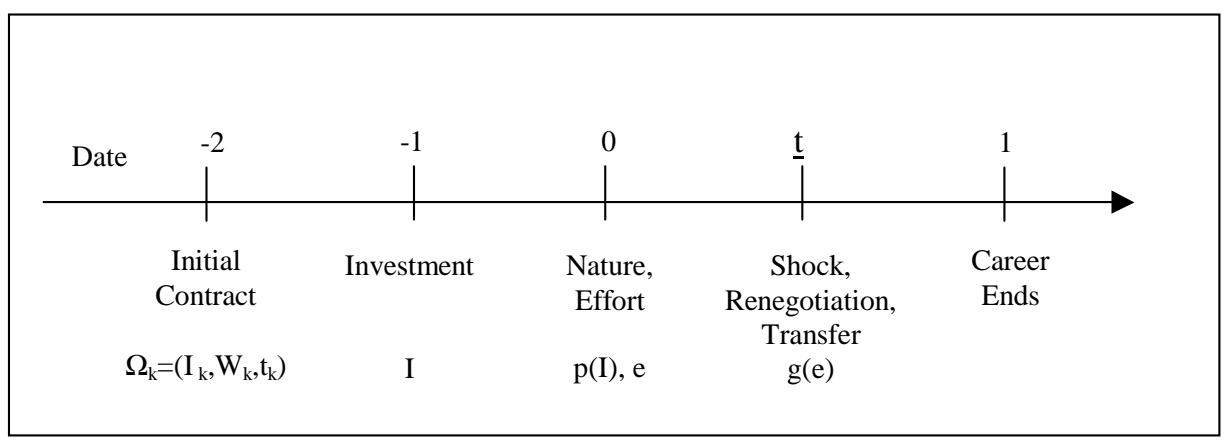

Figure 1: Sequence of Events

\section{$3 \quad$ Renegotiation and payoffs}

Legal situation As explained in the introduction, we consider three different legal situations: the Pre-Bosman situation " $P$ " valid until 1996, the Bosman situation " $B$ " still valid, and the Monti system " $M$ " currently approved. To describe these situations formally, it is instructive to define $r^{l c}$ as the legally fixed transfer fee per unit of time which club $i$ must accept if the player wants to join club $h$ at date $\underline{t}$ under legal system $l \in L=\{P, B, M\}$, and under contract situation $c \in C=\{V, N\} . V$ indicates that the player still has a valid contract, whereas $N$ means that the contract has expired. Defining $r^{l c}$ per unit of time is analytically convenient, and has the advantage that the transfer fee actually paid in equilibrium can be expressed as a function of the remaining contract length. ${ }^{7}$ Table 1 summarizes $r^{l c}$ under the different scenarios:

so that he could get a higher salary in his initial club after his contract has expired as well. However, this would only reinforce our results at the expense of a much more complicated model.

${ }^{7}$ The legally fixed transfer fee under systems $\mathbf{B}$ and $\mathbf{M}$ do not depend on the remaining contract length. However, the results would clearly not change if we used the total transfer fee instead of the fee per unit of time. 


\begin{tabular}{|c|c|c|}
\hline & Valid contract $(V)$ & No contract $(N)$ \\
\hline Pre-Bosman $(P)$ & $r^{P V}=\infty$ & $r^{P N}<\infty$ \\
\hline Bosman $(B)$ & $r^{B V}=\infty$ & $r^{B N}=0$ \\
\hline Monti $(M)$ & $r^{M V}<\infty$ & $r^{M N}=0$ \\
\hline
\end{tabular}

Table 1: Transfer fee club $i$ must accept

If the player wants to join club $h$ when his contract is still valid, then systems $P$ and $B$ are identical, since there is no transfer fee club $i$ must accept from any other club. Conversely, club $i$ 's maximum compensation is bounded under system $M$ even in case of a valid contract. Hence, $r^{M V}<\infty$. For the period where the contract has expired, club $i$ gets nothing after the Bosman judgement $\left(r^{B N}=r^{M N}=0\right)$, but $r^{P N}>0$ under system $P$. Note that under all regimes, the fee club $i$ must accept is higher if the player has a valid contract, i.e. $r^{l V}>r^{l N} \forall l$. As for system $M$, we could also take into account that the maximum contract length is bounded. However, it will become clear that this has the same impact as restricting the transfer fees for valid contracts, so that we can safely ignore this aspect in our model.

Renegotiation If the shock occurs, then all parties can be better off by agreeing on the transfer regardless of $r^{l c}$. However, $r^{l c}$ (and thus, the transfer system) determines the payoff distribution in the renegotiation game. Note that, depending on $r^{l c}$, all three parties are potentially needed for the transfer. We define $\alpha\left(r^{l c}\right), \gamma\left(r^{l c}\right)$ and $\tau\left(r^{l c}\right)$ as the payoffs of club $i$, the player and club $h$, respectively. All payoffs are expressed per unit of time. For short, we will write $\alpha^{l c}, \gamma^{l c}$ and $\tau^{l c}$. Of course, payoffs add up to the total value of the player when playing in club $h$, i.e. $\alpha^{l c}+\gamma^{l c}+\tau^{l c}=h \forall r^{l c}$.

For the specification of the renegotiation game, we adopt the approach by Burguet, Caminal, and Matutes (2001) and decouple the three-person-bargaining game by assuming that if the shock occurs, the player simultaneously bargains with club $i$ and club $h$ (Nash-Bargaining), where his bargaining power is $(1-\beta)$ in both negotiations. Recall that total wages $W$ in the initial club are paid up-front. This implies that in the renegotiation game, the wage rate in the initial club is zero. The result of this game is then as stated in the following lemma. All proofs appear in the appendix. 
Lemma 1 In the renegotiation game,

i) if $r^{l c}>\bar{r} \equiv \frac{1}{1+\beta}(\beta h+\underline{e})$, then $r^{l c}$ is non-binding, and the payoffs per unit of time are independently of $r^{l c}$ given by:

$$
\alpha=\frac{\beta h+\underline{e}}{1+\beta}, \gamma=\frac{(1-\beta)(h-\underline{e})}{1+\beta} \text { and } \tau=\frac{\beta(h-\underline{e})}{1+\beta} .
$$

ii) if $r^{l c} \leq \bar{r} \equiv \frac{1}{1+\beta}(\beta h+\underline{e})$, then $r^{l c}$ is binding and the payoffs are:

$$
\alpha=r^{l c}, \gamma=(1-\beta)\left(h-r^{l c}\right) \text { and } \tau=\beta\left(h-r^{l c}\right) .
$$

iii) club i's payoff per unit of time is weakly increasing in $r^{l c}$, the player's and club $h$ 's payoff is weakly decreasing in $r^{l c}$.

iv) club i's (the players and club h's) payoff per unit of time is weakly higher (lower) if the player has a valid contract, i.e. $\alpha^{l V} \geq \alpha^{l N}, \gamma^{l V} \leq \gamma^{l N}$ and $\tau^{l V} \leq \tau^{l N}$. Moreover, for all participants, the (absolute) difference of the payoff when the player has a valid contract compared to the case of an expired contract is maximum under regime $B$.

Intuitively, if $r^{l c}$ is too high, then club $h$ would not be willing to hire the player. As a result, club $i$ has to accept a lower actual transfer fee to realize the transfer. Thus, it is of no importance if a legal transfer fee for a top player is 400 or 700 billion Euro, because the actual transfer fee will be substantially lower anyway. On the other hand, if $r^{l c}$ is low enough, then it is binding in the sense that club $i$ 's payoff is simply $\alpha=r^{l c}$. Moreover, our bargaining game leads to the intuitive result that club $i$ 's payoff is weakly increasing in $r^{l c}$, where the qualifier "weakly" refers to the fact that $r^{l c}$ ceases to be binding above the threshold level $\bar{r}$. On the other hand, the player's and club $h$ 's stakes are the higher, the lower is $r^{l c}$, because their joint surplus is higher for low values of $r^{l c}$. Since $r^{l V}>r^{l N}$ $\forall l$, this also implies that under any regime, club $i$ 's payoff is higher if the player has a valid contract when the shock occurs, while the opposite is true for the player and club $h$. The difference of the stakes is maximal under regime $\mathrm{B}$, since the transfer fee is nonbinding for valid contracts and zero for expired contracts. Under regime $P$, the transfer fee for expired contracts is positive $\left(r^{P N}>0\right)$, and under regime $M$ it is bounded even for valid contracts $\left(r^{M V}<\infty\right)$. We show in section 4 that this implies that under regime 
B the set of implementable utility levels for the player in case of a transfer is maximal, which is important for his effort choice.

Note that if $r^{M V}>\bar{r}$, then systems $M$ and $B$ are identical. Furthermore, if $r^{P N}>\bar{r}$, it would not matter under system $P$ if a player has a valid contract or not. To avoid these odd situations, we assume that the transfer fees for expired contracts under regime $P$, and the transfer fee for valid contracts under regime $M$ are binding (i.e. not too high). Formally, this amounts to

Assumption $1 r^{P N}, r^{M V}<\bar{r} \equiv \frac{1}{1+\beta}(\beta h+\underline{e})$.

Payoffs Denote by $\Pi_{i}^{l}, U^{l}$ and $\Pi_{h}^{l}$ club $i$ 's, the player's and club $h$ 's expected payoffs under system $l \in L$, respectively. Note that under all systems, we can safely confine attention to the case $t \in[\underline{t}, 1]$, since the player plays for club $i$ until $\underline{t}$ anyhow. We can now express the expected payoffs depending on the regime as follows:

$$
\begin{aligned}
& \Pi_{i}^{l}=-I^{l}+p\left(I^{l}\right)\left\{\underline{t} e^{l}-W^{l}+g\left(e^{l}\right)^{\mathfrak{f}}(t-\underline{t}) \alpha^{l V}+(1-t) \alpha^{l N^{\mathfrak{\alpha}}}+{ }^{\mathbf{i}} 1-g\left(e^{l}\right)^{\boldsymbol{\Phi}}(1-\underline{t}) \underline{e}(1)\right. \\
& U^{l}=p\left(I^{l}\right) \cdot\left\{W^{l}+g\left(e^{l}\right)^{\mathbf{f}}(t-\underline{t}) \gamma^{l V}+(1-t) \gamma^{l N^{\mathfrak{a}}}-c\left(e^{l}\right)\right\} \\
& \Pi_{h}^{l}=p\left(I^{l}\right) \cdot g\left(e^{l}\right) \cdot \mathfrak{f}^{\mathbf{f}}(t-\underline{t}) \tau^{l V}+(1-t) \tau^{l N^{\mathfrak{\alpha}}}
\end{aligned}
$$

As an example, let us consider club $i$ 's expected profit: First of all, club $i$ invests $I^{l}$ in the talent who becomes a player with probability $p\left(I^{l}\right)$. In this case, club $i$ certainly gets $e^{l}$, the productivity of the player until period $\underline{t}$, and pays total wages $W^{l}$. With endogenous probability $g\left(e^{l}\right)$, the shock occurs at date $\underline{t}$. In this case, club $i$ gets $\alpha^{l V}$ per unit of time until the contract expires (i.e. for $t-\underline{t}$ ). For period $1-t$, club $i$ only gets payoff $\alpha^{l N}<\alpha^{l V}$. Finally, with probability $1-g\left(e^{l}\right)$ no shock occurs and the player keeps playing for club $i$ with minimum productivity $\underline{e}$. $U^{l}$ and $\Pi_{h}^{l}$ can be interpreted analogously. Using Lemma 1, the payoffs under all regimes are shown in Table 2 (see Appendix A below). Finally, by adding up the expected payoffs of all participants, we obtain expected social welfare, i.e.

$$
S W^{l}=\Pi_{i}^{l}+U^{l}+\Pi_{h}^{l}=-I^{l}+p\left(I^{l}\right)^{\mathfrak{f}} \underline{t}^{l}-c\left(e^{l}\right)+g\left(e^{l}\right)(1-\underline{t}) h+\left(1-g\left(e^{l}\right)\right)(1-\underline{t}) \underline{e}^{\mathfrak{\alpha}}
$$




\section{Initial contract and results}

The player's maximization problem Since the player's effort $e$ is non-verifiable, his effort decision depends only on the consideration that exerting effort might lead to a lucrative transfer. Suppose the talent has signed contract $\Omega_{i}$, and has become a player. Define $u^{l}(t)$ and $\pi_{h}^{l}(t)$ as the player's utility and club $h$ 's profit, respectively, following a shock, i.e.

$$
\begin{aligned}
u^{l}(t) & \equiv{ }^{\mathbf{f}}(t-\underline{t}) \gamma^{l V}+(1-t) \gamma^{l N} \mathfrak{\alpha} \\
\pi_{h}^{l}(t) & \equiv{ }^{\mathbf{f}}(t-\underline{t}) \tau^{l V}+(1-t) \tau^{l N^{\alpha}}
\end{aligned}
$$

$u^{l}(t)$ and $\pi_{h}^{l}(t)$ are both decreasing in the contract length $t$ and in the transfer fee $r^{l c}$ : if $t$ increases, both get the lower payoffs $\gamma^{l V}<\gamma^{l N}$ and $\tau^{l V}<\tau^{l N}$ for a longer period of time, and $\gamma^{l c}$ and $\tau^{l c}$ are both weakly decreasing in $r^{l c}$ (see Lemma 1 iii)). Under each system, the player will then choose an effort level $b$ which maximizes his expected utility, i.e.

$$
\mathbf{b}(u) \in \arg \max _{e^{l}} W^{l}-c\left(e^{l}\right)+g\left(e^{l}\right) u^{l}(t)
$$

Our assumptions on $c(e)$ and $g(e)$ ensure that $\frac{\partial}{\partial u} \boldsymbol{b}(\cdot)>0$ and $\frac{\partial^{2}}{\partial u^{2}} \boldsymbol{b}(\cdot)<0$. The player's optimal effort choice reveals the disadvantage of high transfer fees and long term contracts: the lower the player's stake in the renegotiation game (i.e. the lower $\gamma^{l c}$ ), the lower $u^{l}$, the lower his incentive to exert effort and to increase the probability of a higher productivity. Note also that $b$ is uniquely determined by $u^{l}(t)$, regardless of whether $u^{l}(t)$ is implemented via a strict transfer system and low $t$, or via a lax system and high $t$, for instance.

The initial contract At date -2 , clubs compete by offering contracts $\Omega_{k}=\left(I_{k}, t_{k}\right.$, $\left.W_{k}\right)$. Define $J S^{l}$ as the player's and club $i$ 's total joint surplus:

$$
J S^{l} \equiv U^{l}+\Pi_{i}^{l}=-I^{l}+p\left(I^{l}\right) \cdot j s^{l},
$$


where $j s^{l} \equiv \underline{t} \boldsymbol{b}-c(\boldsymbol{b})+g(\boldsymbol{b}) \stackrel{\mathfrak{f}}{u^{l}}(t)+(t-\underline{t}) \alpha^{l V}+(1-t) \alpha^{l N^{\mathfrak{a}}}+(1-g(\boldsymbol{b}))(1-\underline{t}) \underline{e}$ denotes the player's and club $i$ 's joint surplus under regime $l$ in case the talent becomes a player. Furthermore, define and $\mathbf{p}$ as the maximizers of the $J S^{l}$ with respect to $t^{l}$ and $I^{l}$, respectively:

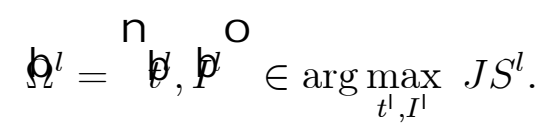

Note that also maximizes $j s^{l}$, because $\hat{I}^{l}$ (and hence $p\left(\hat{I}^{l}\right)$ ) are independent of $t^{l}$. Moreover, the wage $W^{l}$ is a pure distributional matter in the initial contract. However, it will act as to equilibrate the profits of both clubs as the following result shows:

\section{Lemma 2 In equilibrium,}

i) both clubs offer contract $\mathbf{Q} l$,

ii) expected profits of clubs are identical, i.e. $\Pi_{1}^{l}=\Pi_{2}^{l}$ (and hence, $\Pi_{i}^{l}=\Pi_{h}^{l}$ ),

iii) the player is indifferent and accepts each club's offer with probability 0.5 .

To further characterize the contract that maximizes the player's and club $i$ 's joint surplus, it will turn out to be useful to express club $i$ 's and the player's joint maximization problem at date -2 as a function of $u^{l}$ (the player's benefit from a shock), and to define $b^{l}$ as follows: ${ }^{8}$

$$
\begin{aligned}
& \boldsymbol{b}^{l} \in \arg \max _{u^{l}} J S^{l}=-I^{l}+p\left(I^{l}\right)^{\stackrel{\mathbf{f}}{t} \boldsymbol{b}}\left(u^{l}\right)-c\left(\mathbf{b}\left(u^{l}\right)\right)^{\boldsymbol{\alpha}}
\end{aligned}
$$

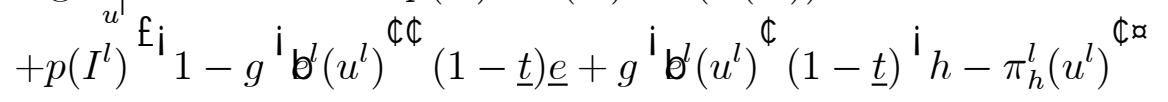

subject to the player's effort decision given by Eqn. (6). The last term in square brackets expresses the joint surplus of club $i$ and the player if the shock occurs as the difference between total surplus $h$ and the expected profit of club $h, \pi_{h}^{l}\left(u^{l}\right)$. Note that $u^{l}$ enters $\pi_{h}^{l}$ via the contract length $t$ required to implement a certain level of $u^{l}$ under regime $l$. Thus, when designing the optimal contract at date -2 , club $i$ and the player are facing

\footnotetext{
${ }^{8}$ Clearly, different t's are required to implement the same $u$ for different legal systems, since the function $\mathrm{u}^{\prime}(\mathrm{t})$ varies with $\mathrm{I}$. For the comparison of the systems, however, it is useful to treat $\mathrm{u}$ as the choice variable. Afterwards, the contract length $t^{\prime}$ required to implement a certain level of $u$ under regime I can be determined.
} 
the following trade off: On the one hand, the player's effort is increasing in $u^{l}$. On the other hand, $\pi_{h}^{l}\left(u^{l}\right)$, and hence the size of the externality is also increasing in $u^{l}$. In what follows, we assume that $\boldsymbol{b}^{l}$ is interior. The following lemma then provides an important result:

Lemma 3 The contract chosen by club $i$ and the player induces the same level of $u$ regardless of the transfer system, i.e. $\boldsymbol{b}^{P}=\boldsymbol{b}^{B}=\boldsymbol{b}^{M} \equiv \boldsymbol{b}$.

Lemma 3 states that club $i$ and the player wish to implement a utility level for the player in case of the shock which is independent of the legal system. The reason is that the function $\pi_{h}(u)$ is identical under all legal systems. Hence, at the margin, the trade-off between the player's incentive problem and club $h$ 's windfall profit is the same under all systems.

Recall from Lemma $1 \mathrm{iv)} \mathrm{that} \mathrm{the} \mathrm{difference} \mathrm{of} \mathrm{the} \mathrm{player's} \mathrm{payoff} \mathrm{in} \mathrm{the} \mathrm{renegotiation}$ game between expired and valid contracts is maximal under regime $B$. This also implies that the set of feasible $u$ 's that can be implemented by varying the contract length is largest under regime $B$. In what follows, we assume that $\boldsymbol{b}$ is feasible under the Bosman system. Otherwise, we would have corner solutions under all regimes, since the player and club $i$ would try to get as close as possible to $b$ by choosing either $t=\underline{t}$ or $t=1$. For regimes $M$ and $P$, the following lemma gives conditions under which $\boldsymbol{b}$ is implementable:

Lemma 4 i) Under system $P$, b is only feasible if $r^{P N}$ is not too high, i.e. $r^{P N} \leq \mathbf{e} \equiv$ $\frac{(1-\underline{t}) \cdot(1-\beta) \cdot h-\underline{b}}{(1-\underline{t}) \cdot(1-\beta)}$.

ii) Under system $M, \boldsymbol{b}$ is only feasible if $r^{M V}$ is not too low, i.e. $r^{M V} \geq \mathbf{e} \equiv \frac{(1-\underline{t}) \cdot(1-\beta) \cdot h-\boldsymbol{b}}{(1-\underline{t}) \cdot(1-\beta)}$.

iii) The set of implementable $u$ is largest under regime $B$.

Under system $P$, the maximal $u$ which can be implemented is lower than under system $B$, as the player's stake in case of an expired contract is only $\gamma^{P N}=(1-\beta)\left(h-r^{P N}\right)<\gamma^{B N}$ (see table 2 in Appendix A). Thus, the maximal level of $u$ which can be implemented might induce insufficient effort incentives. Figure 2(a) depicts a case in which $\boldsymbol{b}$ is not implementable under regime $P$. Analogously, under regime $M$, the minimal level of $u$ which can be implemented is higher than under regime $B$, since the player's stake in case of a valid contract is $\gamma^{M V}=(1-\beta)\left(h-r^{M V}\right)>\gamma^{B V}$. Thus, the minimum level of $u$ 
which can be implemented might induce too high levels of effort and of $\pi_{h}(u)$. In reality, this effect is reinforced by the fact that the maximum contract length is restricted under system $M$. The case in which $\boldsymbol{b}$ is not implementable under regime $M$ is depicted in Figure 2(b).

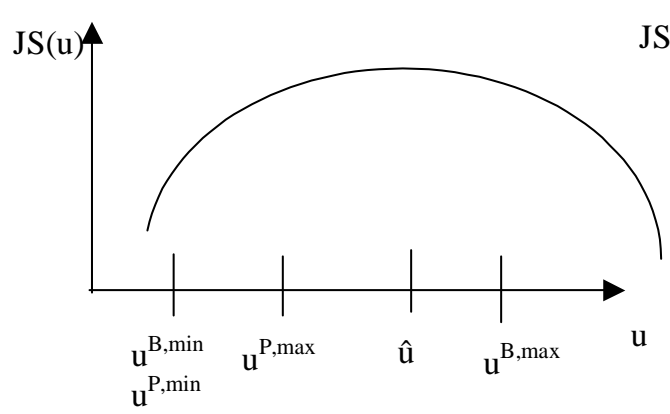

(a)

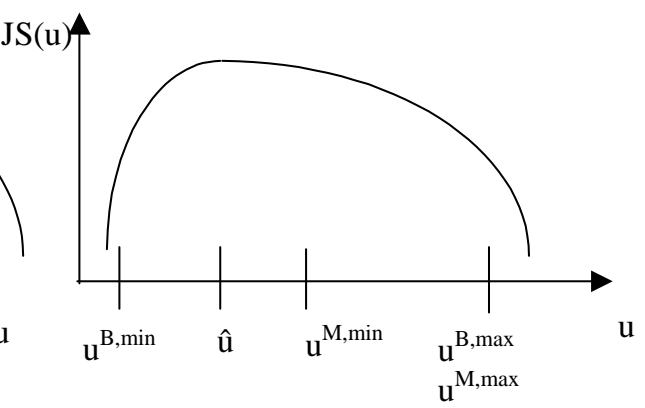

(b)

Figure 2: $\emptyset$ not feasible under regimes $P$ and $M$, respectively.

This leads to our next result:

Proposition 1 Suppose $r^{M V} \geq \mathbf{e}$ and $r^{P N} \leq \mathbf{e}$. Then, in equilibrium, the outcome is identical under all regimes except for the contract length for which we have $t^{P}<t^{B}<t^{M}$.

The intuition for Proposition 1 is that the player's effort $(e)$, club $h$ 's profit in case a shock occurs $\left(\pi_{h}^{l}\right)$ and the player's and club $i$ 's expected joint surplus $(J S)$ are all uniquely determined by $u$. Hence, as long as the player and club $i$ can implement $\emptyset$ via $t^{l}$, nothing changes except the contract length. The idea is straightforward: since $\pi_{h}^{l}(u)$ is independent of $l$, the trade-off between investment and effort incentives is the same under all regimes, so that the optimal $u$ must also be independent of $l$. That $t^{P}<t^{B}<t^{M}$ follows from the fact that the contract length required to implement $\boldsymbol{b}$ is the higher the laxer the transfer system. For instance, regime $P$ would generate too low a level of $u$ for $t^{P}=t^{B}$ since $\gamma^{P N}>\gamma^{B N}$ (see Lemma $\left.1 \mathrm{iv}\right)$ ). Therefore, the period with a valid contract must be shorter under regime $P$ to adjust for this. Casual observation suggests that the average contract length has indeed increased after the Bosman judgement. Proposition 1 predicts that the contract length will further increase after the Monti system is enacted.

We now turn to the comparison of regimes $B$ and $P$ under the assumption that $b$ cannot be reached under $P$, where the following results hold: 
Proposition 2 Suppose system $P$ matters, i.e. $r^{P N}>$ e. Then, in equilibrium

\begin{tabular}{|l|l|l|l|}
\hline i) & $u^{P}<u^{B}$ & ii) & $e^{P}<e^{B}$ \\
\hline iii) & $J S^{P}<J S^{B}$ & iv $)$ & $I^{P}<I^{B}$ \\
\hline v) & $S W^{P}<S W^{B}$ & vi) & $t^{P}=\underline{t}$ \\
\hline vii) & $\Pi_{h}^{P}<\Pi_{h}^{B}$ & viii) & $\Pi_{i}^{P}<\Pi_{i}^{B}$. \\
\hline
\end{tabular}

The most important point in Proposition 2 is that social welfare under system $P$ is strictly lower compared to system $B$ in this case (see part v)). The reason is that the player's benefit from the transfer is too low from the player's and club $i$ 's ex ante point of view: they would like to induce the player to exert more effort at the expense of a higher payoff for club $h$, but they are restricted if $r^{P N}>\mathbf{e}$. Therefore, e, JS and $I$ are lower. As for expected social welfare, note that $S W$ is increasing in $e$ for $e<\boldsymbol{b}$, since the Pareto optimal effort is given by $g^{\prime}(1-\underline{t})(h-\underline{e})=c^{\prime}$, and $u<(1-\underline{t})(h-\underline{e})$. Furthermore, $S W$ is also increasing in $I$ for $I=\mathfrak{p}$, since, when deciding on $I$, the initial club and the player

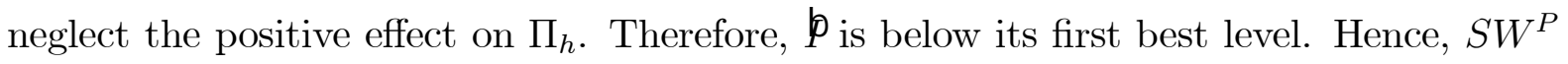
$<S W^{B}$. Finally, club $i$ and the player try to mitigate the problem that the player's stake in the renegotiation game is too low by choosing the minimal time for which the player has the low payoff $\gamma^{P V}$, i.e. $t^{P}=\underline{t}$. Note that, although expected social welfare is lower, we cannot rule out that the player's expected utility is higher under regime $P$ compared to regime $B$. The reason is that equilibrium profits are lower, because club $h$ 's payoff, and according to Lemma 2 also club $i$ 's payoff are lower compared to $b$. Without further assumptions, one cannot exclude that the effect of decreasing profits overcompensates the effect of decreasing welfare, so that the player's utility would be increasing.

Comparing systems $M$ and $B$ for the case in which $b$ is not implementable under regime $M$, our findings can be summarized in 
Proposition 3 Suppose system $M$ matters, i.e. $r^{M V}<$ e. Then, in equilibrium

\begin{tabular}{|l|l|l|l|}
\hline i) & $u^{M}>u^{B}$ & ii) & $e^{M}>e^{B}$ \\
\hline iii) & $J S^{M}<J S^{B}$ & iv) & $I^{M}<I^{B}$ \\
\hline v) & $S W^{M} \lessgtr S W^{B}$ & vi) & $t^{M}=1$ \\
\hline vii) & $\Pi_{h}^{M}>\Pi_{h}^{B}$ & viii) & $\Pi_{i}^{M}>\Pi_{i}^{B}$. \\
\hline
\end{tabular}

If $r^{M V}<\mathbf{e}$, then regime $M$ leads to a higher payoff from the renegotiation game for the player $\left(u^{M}>\mathbf{b}\right)$ than the player and club $i$ wish to implement ex ante. Hence, system $M$ mitigates the effort problem $\left(e^{M}>e^{B}\right)$. On the other hand, system $M$ leads to lower $J S$ by definition of $\boldsymbol{b}$. Hence, $I^{M}<I^{B}$. Since the joint payoff of the player and club $h$ from the renegotiation game is always too high under regime $M$, the player and club $i$ will reduce its impact by choosing the maximum contract length $t^{M}=1$. Whether expected social welfare under $M$ is higher or lower compared to $B$ depends on the relative importance of the problem of non-verifiable effort compared to the underinvestment problem, and thus on the parameters of our model: If there is no investment problem (for example if $p$ were exogenous), the Monti system is certainly superior, because overall welfare then depends only on $e$. On the other hand, if there is no problem with non-verifiable effort (for example if effort were too $\operatorname{costly}^{9}$ ), then system $B$ is superior, because $I$ (and hence social welfare) is strictly increasing in $J S$.

\section{Discussion}

We have compared the Pre-Bosman regime, the Bosman regime and the recently approved Monti regime in a model in which the probability that a talent becomes a professional depends on the initial club's investment. Furthermore, the player's non-verifiable effort determines not only his performance in his own club, but also the probability that he reaches a higher productivity elsewhere. Under these circumstances, the player's effort is the higher the higher his net benefit in case a transfer takes place. The problem when designing the initial contract is that a higher stake for the player inevitably also leads

\footnotetext{
${ }^{9}$ Formally, this can simply be ensured by assuming that $c^{9}(\underline{e})=\infty$.
} 
to a higher payoff of the new club since both depend on the contract length, and hence ceteris paribus leads to lower investment incentives due to the externality problem. In the initial contract, the contract length is then chosen such that the marginal gain from higher effort equilibrates the marginal loss from lower stakes in the renegotiation game.

One main result is that this trade-off is the same under all legal regimes. As a result, the optimal contract leads to the same effort, investment incentives and payoffs by varying the contract length. However, the player's maximal stake from renegotiation may be too low under the Pre-Bosman system compared to what the optimal contract would stipulate. In this case, the Pre-Bosman system is inferior since it leads to lower investments and to lower effort, so that there may have been good reasons to switch to the Bosman system. In the Monti system, the player's minimal stake may be too high. Our analysis then leads to ambiguous results with respect to social welfare, since the investment is lower and the effort higher compared to Bosman.

In reality, the trade-off between the investment and the effort problem may vary from player to player, especially because there are players with high intrinsic motivation (i.e. low effort costs), whereas only the perspective of higher future salaries may motivate other players. Hence, one would expect to observe maximum contract lengths' for players where the effort problem is not that important under regime $M$, whereas shorter contracts may be chosen for other players. Restricting the contract length and the transfer fees for all players in the same way then causes problems, because club $i$ 's and the player's possibilities to adjust for specific circumstances are restricted. Therefore, an interesting extension might be to compare the Bosman regime to the Monti system under the assumption that the regulator is imperfectly informed about the effort and the investment problem, and then tries to maximize social welfare.

A number of assumptions underlie our analysis. First, our assumption that total wages are paid up-front implies that the renegotiation game is independent of the wage, and only determined by the legal system and the contract length. The main analytical advantage is that the effort choice is then also independent of the wage, so that the wage is only used to make the two clubs' profits equal. However, the assumption is not crucial for the results: if one assumes instead that the player receives the same wage in club $i$ after $\underline{t}$ if he does not change clubs, then his threat point and his wage in case he joins 
club $h$ are increasing. We have shown in an extension of the renegotiation game that the derivative of the new wage with respect to the wage in club $i$ is equal to 1 in case the transfer fee is non-binding, and $\beta<1$ in case the transfer fee is binding. In the first case, the player's effort choice is the same regardless of whether total wages are paid up-front or not. In the second case, the effort decreases, so that the player and club $i$ would have an incentive to pay wages up-front. Since the analysis then turns out to be far from straightforward, our assumption seems to be justified for reasons of tractability.

Second, we assume that the investment is contractible to illuminate that the underinvestment problem is not caused by an incomplete contracting problem between the initial club and the player, but by the fact that the talent will possibly play for a club which has not invested in the talent's education. If $I$ were not contractible, then the investment would not depend on the player's and club $i$ 's joint surplus, but only on club $i$ 's expected profit. This would lead to a higher contract length, since the player and club $i$ would ex ante have an incentive to increase club $i$ 's expected profit. The main results would not change, but the model became much more complicated due to an additional incentive constraint.

Third, we capture all negative effects of long-term contracts by assuming that the player's effort (and hence the probability for positive shocks) is increasing in the player's net benefit from the transfer in the renegotiation game. There may be other negative aspects caused by long-term contracts worthy of consideration, for instance that the club's flexibility is reduced when engaging a new coach, or when switching to an other tactical system. However, this would have no effect as long as there is no asymmetric information, since the Coase theorem again predicts that the player changes clubs whenever his performance is higher elsewhere. The same holds for the possibility of disability over time, which would only constitute a negative effect if the disabled player fails to adopt productive outside options because he is protected by a long-term contract. If this is not the case, then there is only a redistribution effect that might even be warranted if the player is risk-averse. Hence, we believe that capturing the negative effects of long-term contracts via a lower effort caused by a lower ex-post benefit from renegotiation is fairly realistic. 


\section{Appendix}

\section{A Proof of Lemma 1}

Recall that all values are expressed per unit of time. We have to consider two cases: in part i) of the lemma, $r^{l c}$ is binding, in part ii) it is non-binding. Note that club $i$ 's payoff $\alpha$ is identical to the actual transfer paid by club $h$. Denote by $z$ the actual transfer which is paid by club $h$. Then, if $r^{l c}$ is binding, we have $z=r^{l c}$. If $r^{l c}$ is non-binding, then we have $z<r^{l c}$. Furthermore, the player's wage in $\operatorname{club} h$ is denoted $w^{h}$. Since the analysis holds for all $r \in[0, \infty]$, we omit superscripts from now on.

Part $\mathbf{i}): r$ is non-binding. In the bargaining between club $i$ and the player, we will show that $r$ is non-binding if it is above some threshold value $\bar{r}$. We assume that the player keeps playing for club $i$ if negotiations break down. ${ }^{10}$ Therefore, in the threat point, club i gets $\underline{e}$ while the player gets zero (recall that his wage is paid up-front). The joint surplus to share for club $i$ and the player in case of a transfer is $w^{h}+z-\underline{e}$, that is the sum of the wage paid by club $h$ and the transfer fee. Thus, the payoffs per unit of time are

$$
\begin{aligned}
& \alpha=\underline{e}+\beta\left(w^{h}+z-\underline{e}\right) \\
& \gamma=0+(1-\beta)\left(w^{h}+z-\underline{e}\right)
\end{aligned}
$$

In the bargaining between the player and club $h$, the threat point payoff is zero for both parties, and the surplus to share is $h-z$. Hence, the payoffs are

$$
\begin{aligned}
& \tau=0+\beta(h-z) \\
& \gamma=0+(1-\beta)(h-z) .
\end{aligned}
$$

Finally, total payoffs must add up to $h$, i.e.

$$
\alpha+\gamma+\tau=h
$$

Thus, since all equations must hold simultaneously, we have five equations for five endogenous variables, $\alpha, \gamma, \tau, z$ and $w^{h}$. Solving the equation system yields

$$
\begin{aligned}
\alpha & =z=\frac{\beta h+\underline{e}}{1+\beta}, \\
\gamma & =w^{h}=\frac{1-\beta}{1+\beta}(h-\underline{e}) \\
\tau & =\frac{\beta}{1+\beta}(h-\underline{e}) .
\end{aligned}
$$

\footnotetext{
${ }^{10}$ For $\mathrm{h}>\mathrm{r}$, one might argue that the player could afford to pay $\mathrm{r}$ and leave in case negotiations break down (provided that the wage in club $h$ is higher than $r$ ). This would lead to the implausible result that club $\mathrm{i}$ could benefit from a breakdown of the negotiations. Moreover, that the player pays $r$ in this case would imply that he has full the bargaining power in a bilateral problem between club $\mathbf{i}$ and the player, which we believe not to be plausible.
} 
Note that $r$ is not only binding for $r>\underline{e}$, but whenever it is larger than the equilibrium transfer fee $z=\frac{1}{1+\beta}(\beta h+\underline{e})$ which is larger than $\underline{e}$ since $h>\underline{e}$.

Part ii): $r$ is binding From the discussion in part i), it follows that $r$ is binding if $r \leq \frac{1}{1+\beta}(\beta h+\underline{e})$. Club $i$ is now a "dummy player" who always gets $r$, i.e. $\alpha=z=r$.

In the game between the player and club $h$, the threat points are again $(0,0)$. The joint surplus to share is $h-r$, therefore the payoffs per unit of time are $\gamma=(1-\beta)(h-r)$ and $\tau=\beta(h-r)$.

Part iii): Weak Monotonicity Given the anzalysis in parts i) and ii), it follows that the actual transfer fee club $i$ gets is $z=\begin{array}{ll}r & \text { if } r \leq \bar{r} \\ \frac{1}{1+\beta}\left(\beta h \frac{1}{1 / 2} \underline{e}\right) & \text { if } r>\bar{r}\end{array}$. Thus, $z$ is

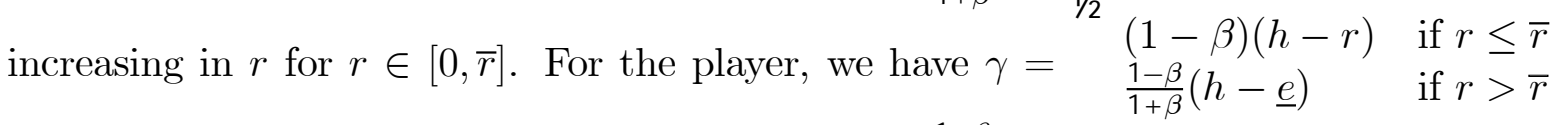
which is decreasing on $\left[0, \bar{r} \frac{\bar{r}}{2}\right]$ and $(1-\beta)(h-r)-\frac{1-\beta}{1+\beta}(h-\underline{e}) \geq 0$ for $r \leq \bar{r}$. Finally, for club $h$ we have $\tau=\begin{array}{ll}\beta(h-r) & \text { if } r \leq \bar{r} \\ \frac{\beta}{1+\beta}(h-\underline{e}) & \text { if } r>\bar{r}\end{array}$. Again, $\tau$ is decreasing on $[0, \bar{r}]$ and $\beta(h-r)-\frac{\beta}{1+\beta}(h-\underline{e}) \geq 0$ for $r \leq \bar{r}$.

Part iv): Difference of payoffs That club i's (the player's and club $h$ 's) payoff is higher (lower) if the player has a valid contract under either regime, follows directly from $r^{l V}>r^{l N} \forall l$ and part iii) of the lemma. Moreover it can easily be checked using table 2 below.

To show that for all participants, the difference is maximal under regime $\mathrm{B}$, define $\alpha^{l}$ as the difference of club i's stake for expired and valid contracts under regime $l$, i.e. $\alpha^{l} \equiv \alpha^{l N}-\alpha^{l V}$. Define $\gamma^{l}$ and $\tau^{l}$ respectively. We have to show that $\alpha^{B}>\alpha^{P}, \alpha^{M}$, $\gamma^{B}>\gamma^{P}, \gamma^{M}$ and $\tau^{B}>\tau^{P}, \tau^{M}$. We confine attention to club $i$, since the proof for club $h$ and the player proceeds analogously. Note that $\alpha^{l}<0$ as club $i$ is worse off with expired contracts-under all regīmes. Using again the entries from table $\underline{2}$ below, for regime $B$ we have ${ }^{-} \alpha^{B^{-}}={ }^{-} 0-\frac{\beta h+e^{-}}{1+\beta}=\frac{\beta h+e}{-1+\beta}$. For regime $P$ we have ${ }^{-} \alpha^{P^{-}}={ }^{-}{ }^{P N}-\frac{\beta h+e^{-}}{1+\beta}<\frac{\beta h+e}{1+\beta}$ and for regime $M$ we have $\alpha^{B^{-}}=-0-r^{M V^{-}}=r^{M V}<\frac{\beta h+e}{1+\beta} \equiv \bar{r}$ by Assumption 1.

For further reference, the payoffs of all participants under all regimes are summarized in the following table:

\begin{tabular}{|c|c|c|}
\hline Club $i$ & Player & Club $h$ \\
\hline$\alpha^{P V}=\frac{\beta h+e}{1+\beta}$ & $\gamma^{P V}=\frac{1-\beta}{1+\beta}(h-\underline{e})$ & $\tau^{P V}=\frac{\beta}{1+\beta}(h-\underline{e})$ \\
\hline$\alpha^{P N}=r^{P N}$ & $\gamma^{P N}=(1-\beta)\left(h-r^{P N}\right)$ & $\tau^{P N}=\beta\left(h-r^{P N}\right)$ \\
\hline$\alpha^{B V}=\frac{\beta h+e}{1+\beta}$ & $\gamma^{B V}=\frac{1-\beta}{1+\beta}(h-\underline{e})$ & $\tau^{B V}=\frac{\beta}{1+\beta}(h-\underline{e})$ \\
\hline$\alpha^{B N}=0$ & $\gamma^{B N}=(1-\beta) h$ & $\tau^{B N}=\beta h$ \\
\hline$\alpha^{M V}=r^{M V}$ & $\gamma^{M V}=(1-\beta)\left(h-r^{M V}\right)$ & $\tau^{M V}=\beta\left(h-r^{M V}\right)$ \\
\hline$\alpha^{M N}=0$ & $\gamma^{M N}=(1-\beta) h$ & $\tau^{M N}=\beta h$ \\
\hline
\end{tabular}

Table 2: Payoff Summary 


\section{B Proof of Lemma 2}

Part i) To see that both clubs offering $\mathbf{Q}^{l}$ is a Nash-Equilibrium, suppose $\Omega_{2}^{l}=\mathbf{q}^{l}$. Then club 1 can never be better off by offering $\Omega_{1}^{l} \neq \mathbf{Q}^{l}$ : a) if it offers $\Omega_{1}^{l} \neq \mathbf{q}^{l}$ and a wage rate $W_{1}^{l}$ sufficiently high such that the talent joins club 1 , then club 1 could always be better off by offering $\Omega_{1}^{l}=\mathbf{Q}^{l}$, while leaving $W_{1}^{l}$ unchanged: The talent would still join club 1 but the surplus, and thus club 1's profit would be higher. b) if club 1 offers $\Omega_{1}^{l} \neq \mathbf{Q}^{l}$ and a wage rate $W_{1}^{l}$ such that the talent joins club 2 , then club 1's profit is $\Pi_{h}^{l}\left(\Omega^{l}\right)$ which is independent of $\Omega_{1}^{l}$ and $W_{1}^{l}$. A symmetric argument holds for club 2 .

Part ii) In equilibrium, $\Pi_{i}^{l}\left(\mathbf{Q}^{l}, W_{i}\right)=\Pi_{h}^{l}\left(\mathbf{Q}^{l}\right)$ must hold: a) If $\Pi_{i}^{l}\left(\mathbf{Q}^{l}, W_{i}\right)>\Pi_{h}^{l}\left(\mathbf{Q}^{l}\right)$ then club $i$ could lower $W_{i}$ slightly, still educating the talent but obtaining a higher profit. b) If $\Pi_{i}^{l}\left(\mathbf{q}^{l}, W_{i}\right)<\Pi_{h}^{l}\left(\mathbf{Q}^{l}\right)$ then club $i$ could increase its profit by lowering $W_{i}$ such that the talent chooses to be educated in the other club ("becoming club $h "$ ).

It follows that the initial wage $W_{k}^{l}$ acts to equilibrate the expected profit of both clubs, i.e. in equilibrium the initial wage $W_{1}^{l}=W_{2}^{l}=\mathbb{A}^{l}$ is implicitly given by

$$
J S^{l}\left(\mathbf{Q}^{l}\right)-U^{l}\left(\mathbf{Q}^{l}, \boldsymbol{\Phi}^{l}\right)=\Pi_{h}^{l}\left(\mathbf{Q}^{l}\right)
$$

To see that offering $W_{1}^{l}=W_{2}^{l}=\mathbb{G}^{l}$ is consistent with Nash Equilibrium, suppose $W_{2}^{l}=$ $\mathfrak{Q}^{l}$ and consider again a deviation by club 1: a) offering $W_{2}^{l}>\mathscr{Q}^{l}$ leads to lower $\Pi_{1}^{l}$ since

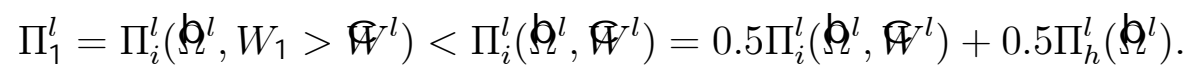

b) offering $W_{2}^{l}<\widehat{Q}^{l}$ does not change club 1's profit, since the talent is educated by club 2 so that club 1 gets $\Pi_{h}^{l}\left(\mathbf{Q}^{l}\right)$. A similar argument holds for club 2 .

Part iii) Since both clubs make identical offers in equilibrium, $\Omega_{1}^{l}=\Omega_{2}^{l}=\mathbf{Q}^{l}$ and $W_{1}^{l}=W_{2}^{l}=\mathbf{A}^{l}$, the talent chooses each club's offer with probability 0.5 .

\section{Proof of Lemma 3}

We will show that $\pi_{h}^{l}(u)$ is independent of the transfer system, i.e. $\pi_{h}^{P}(u)=\pi_{h}^{B}(u)=$ $\pi_{h}^{M}(u) \equiv \pi_{h}(u)=\frac{\beta}{1-\beta} u$. Therefore, provided an interior solution exists, the first order condition for problem (9) will be the same for all regimes, since the functions $e(u), c(e)$ and $g(e)$ are also independent of the regime. Recalling that $b^{l}$ is the privately optimal $u$ under system $l$, the necessary condition for the optimal level of $u$ after rearranging terms is

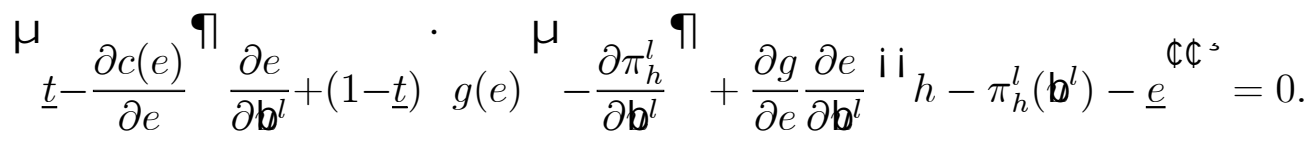

To show that $\pi_{h}^{l}(u) \equiv \pi_{h}(u) \forall l$, we first explicitly derive $u$ by plugging in the outcome from the bargaining game (see Lemma 1). Then, we invert $u(t)$ which gives us the contract 
length $t(u)$ required to induce a certain level of $u .^{11}$ Finally, we substitute this in $\pi_{h}(t)$ to get $\pi_{h}(u)$. The payoffs are taken from table 2 (see Appendix A).

Regime B We have $\gamma^{B V}=\frac{(1-\beta)(h-\underline{e})}{1+\beta}, \gamma^{B N}=(1-\beta) h, \tau^{B V}=\frac{\beta(h-\underline{e})}{1+\beta}$, and $\tau^{B N}=\beta h$. Hence,

$$
\begin{aligned}
u & =(t-\underline{t}) \frac{(1-\beta)}{(1+\beta)}(h-\underline{e})+(1-t)(1-\beta) h \\
& \Leftrightarrow t=\frac{u+\underline{t} \frac{(1-\beta)}{(1+\beta)}(h-\underline{e})-(1-\beta) h}{\frac{(1-\beta)}{(1+\beta)}(h-\underline{e})-(1-\beta) h} \\
& =\frac{(1+\beta) u+\underline{t}(1-\beta)(h-\underline{e})-(1+\beta)(1-\beta) h}{(1-\beta)(h-\underline{e})-(1-\beta)(1+\beta) h} \\
& =\frac{(1+\beta) u+(1-\beta)[\underline{t} h-\underline{t e}-h-\beta h]}{-(1-\beta)(\beta h+\underline{e})}
\end{aligned}
$$

$\pi_{h}^{B}(t)$ can be written as:

$$
\pi_{h}^{B}(t)=t \frac{-\beta(\underline{e}+\beta h)^{\lrcorner}}{(1+\beta)}+\frac{\beta[-\underline{t} h+\underline{t e}+h+\beta h]^{\lrcorner}}{(1+\beta)}
$$

Substituting from (16) yields

$$
\begin{aligned}
\pi_{h}^{B}(u)= & \frac{(1+\beta) u+(1-\beta)[\underline{t} h-\underline{t} e-h-\beta h]^{\lrcorner}}{-(1-\beta)(\beta h+e)} \frac{-\beta(e+\beta h)^{\circ}}{(1+\beta)} \\
& +\frac{\beta[-\underline{t} h+\underline{t e}+h+\beta h]^{\lrcorner}}{(1+\beta)} \\
= & \frac{-\beta(1+\beta) u}{-(1-\beta)(1+\beta)}=\frac{\beta}{(1-\beta)} u .
\end{aligned}
$$

Regime $\mathbf{P}$ Here we have $\gamma^{P V}=\frac{(1-\beta)(h-e)}{1+\beta}, \gamma^{B N}=(1-\beta)\left(h-r^{P N}\right), \tau^{B V}=\frac{\beta(h-\underline{e})}{1+\beta}$, and $\tau^{B N}=\beta\left(h-r^{P N}\right)$. Therefore,

$$
u=(t-\underline{t}) \frac{(1-\beta)}{(1+\beta)}(h-\underline{e})+(1-t)(1-\beta)(h-r) .
$$

Solving for $t$ yields

$$
t=\frac{(1+\beta) u+(1-\beta)[\underline{t}(h-\underline{e})-(1+\beta)(h-r)]}{-(1-\beta)(\underline{e}-r+\beta h-\beta r)} .
$$

\footnotetext{
${ }^{11}$ Note that $\mathrm{u}(\mathrm{t})$ is monotone in $\mathrm{t}$ under all regimes.
} 
Similarly, $\pi_{\mathrm{h}}^{P}(t)$ can be written as:

$$
\pi_{\mathrm{h}}^{P}(t)=t \frac{-\beta(\underline{e}-r+\beta h-\beta r)}{(1+\beta)}+{\frac{\beta[-\underline{t h}+\underline{t e}+h+\beta h-r-\beta r]^{\lrcorner}}{(1+\beta)}}^{\cdot} .
$$

Substituting from (17) yields

$$
\begin{aligned}
\pi_{\mathrm{h}}^{P}(u)= & \frac{(1+\beta) u+(1-\beta)[\underline{t}(h-\underline{e})-(1+\beta)(h-r)]^{\lrcorner}}{-(1-\beta)(\underline{e}-r+\beta h-\beta r)} \frac{-\beta(\underline{e}-r+\beta h-\beta r)}{(1+\beta)} \\
& +\frac{\beta\left[\underline{\underline{t} h+\underline{t}+h+\beta h-r-\beta r]^{\prime}}\right.}{(1+\beta)} \\
= & \frac{-\beta(1+\beta) u}{-(1-\beta)(1+\beta)}=\frac{\beta}{(1-\beta)} u .
\end{aligned}
$$

Regime M Finally, we have $\gamma^{M V}=(1-\beta)(h-r), \gamma^{M N}=(1-\beta) h, \tau^{M V}=\beta(h-r)$, and $\tau^{M N}=\beta h$. Thus,

$$
\begin{aligned}
u & =(t-\underline{t})(1-\beta)(h-r)+(1-t)(1-\beta) h \\
u+\underline{t}(1-\beta)(h-r)-(1-\beta) h & =t[(1-\beta)(h-r)-(1-\beta) h] \\
t & =\frac{u+\underline{t}(1-\beta)(h-r)-(1-\beta) h}{-(1-\beta) r} .
\end{aligned}
$$

$\pi_{h}^{M}(t)$ can be written as:

$$
\pi_{h}^{M}(t)=t[\beta(h-r)-\beta h]-\underline{t} \beta(h-r)+\beta h .
$$

Substituting from (18) yields

$$
\begin{aligned}
\pi_{h}^{M}(u) & =\frac{u+\underline{t}(1-\beta)(h-r)-(1-\beta) h^{\lrcorner}}{-(1-\beta) r}[-\beta r]-\underline{t} \beta(h-r)+\beta h \\
& =\frac{\beta u+\beta[\underline{t}(1-\beta)(h-r)-(1-\beta) h]+(1-\beta)[-\underline{t} \beta(h-r)+\beta h]}{(1-\beta)} \\
& =\frac{\beta u+\beta(1-\beta)[\underline{t}(h-r)-h]-\beta(1-\beta)[\underline{t}(h-r)-h]}{(1-\beta)} \\
& =\frac{\beta}{(1-\beta)} u .
\end{aligned}
$$

Thus, $\pi_{h}^{B}(u)=\pi_{h}^{P}(u)=\pi_{h}^{M}(u)=\frac{\beta}{(1-\beta)} u \equiv \pi_{h}(u)$

\section{Proof of Lemma 4}

We first show that under regime $P(M)$, large (small) levels of $u$ may not be implementable. We then show that the interval of implementable $u$ 's is largest under regime B. 
Part i) We need to show that $\boldsymbol{b}$ cannot be reached under regime $P$ if $r^{P N}$ is too high: First, it is straightforward that $\frac{\partial u}{\partial t}<0$. The maximum level of $u^{P}$ attainable is therefore $u^{P, \max } \equiv u^{P}(t=\underline{t})=(1-\underline{t}) \cdot(1-\beta) \cdot\left(h-r^{P N}\right)$. Thus, $\boldsymbol{b}$ can be implemented by varying $t$ as long as $u^{P, \max } \geq \mathbf{b}$. This holds with equality for $r^{P N}=\frac{(1-\underline{t}) \cdot(1-\beta) \cdot h-\boldsymbol{b}}{(1-\underline{t}) \cdot(1-\beta)}=\mathbf{e}$. Since $u^{P}$ is decreasing in $r^{P N}$, it follows that $\boldsymbol{b}$ cannot be implemented for $r^{P N}>\mathbf{e}$

Part ii) We want to show that $b$ cannot be reached under regime $M$ if $r^{M V}$ is too low. Note first that $u^{M}(t)$ is decreasing in $t$, i.e. $\frac{\partial u^{\mathrm{M}}}{\partial t}=(1-\beta)\left(h-r^{M V}\right)-(1-\beta) h=$ $-\beta\left(h-r^{M V}\right)<0$. The minimum level of $u$ is therefore $u^{M, \min } \equiv u^{M}(t=1)=(1-\underline{t})$. $(1-\beta) \cdot\left(h-r^{M V}\right)$. Thus, $\boldsymbol{b}$ can be reached under regime $M$, if $u^{M, \min } \leq \boldsymbol{b}$. $u^{M, \min }$ is decreasing in $r^{M V}$, therefore, the threshold value is $\mathbf{e} \equiv \frac{(1-\underline{t}) \cdot(1-\beta) \cdot h-\boldsymbol{b}}{(1-\underline{t}) \cdot(1-\beta)}$. Hence, $\boldsymbol{b}$ cannot be reached under regime $M$, if $r^{M V} \leq \boldsymbol{b}$.

Part iii) It remains to show that the interval of implementable $u$ 's is largest under regime B. Again, we have $\frac{\partial u}{\partial t}<0$. Therefore $u^{B, \max } \equiv u^{B}(t=\underline{t})=(1-\underline{t}) \cdot(1-\beta) \cdot h$ and $u^{B, \min } \equiv u^{B}(1)=(1-\underline{t}) \cdot \frac{(1-\beta)}{(1+\beta)} \cdot(h-\underline{e})$. To compare with regime $M$, note that $u^{B, \max }=u^{M, \max }\left(\right.$ since $\left.\gamma^{B N}=\gamma^{M N}\right)$. As to the minimum levels, using the definition of $u^{M, \min }$ in part i), we have

$$
\begin{aligned}
u^{M, \min }-u^{B, \min } & =(1-\underline{t}) \cdot(1-\beta)\left(h-r^{M V}\right)-(1-\underline{t}) \cdot \frac{(1-\beta)}{(1+\beta)}(h-\underline{e}) \\
& =(1-\underline{t}) \frac{(1-\beta)}{(1+\beta)}^{\mathbf{f}} \beta h+\underline{e}-(1+\beta) r^{M V^{\alpha}} \geq 0,
\end{aligned}
$$

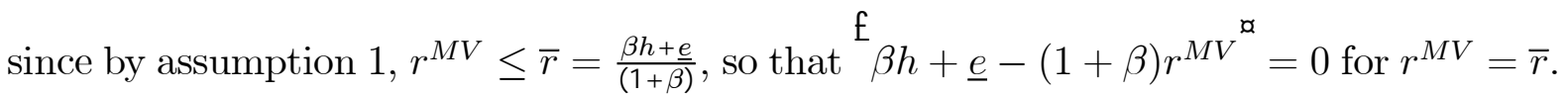

Comparing regimes $B$ and $P$, we know that $u^{B, \min }=u^{P, \min }\left(\right.$ since $\left.\gamma^{B V}=\gamma^{P V}\right)$. Using $u^{P, \max }$ as defined in part ii), we get

$$
\begin{aligned}
u^{B, \max }-u^{P, \max } & =(1-\underline{t}) \cdot(1-\beta) \cdot h-(1-\underline{t}) \cdot(1-\beta) \cdot\left(h-r^{P N}\right) \\
& =(1-\underline{t}) \cdot(1-\beta) \cdot r^{P N}>0
\end{aligned}
$$

Summarizing, we have $u^{B, \min }=u^{P, \min }<u^{M, \min }, u^{P, \max }<u^{B, \max }=u^{M, \max }$.

\section{E Proof of Proposition 1}

Since $b$ maximizes the expected joint surplus of the player and club $i$ at date -2 , it is chosen under all regimes if feasible. Since $e$ depends on $u$ only, $e$ is the same under all regimes. Furthermore, investment incentives are uniquely determined by $J S$, and are hence also identical. As $S W$ depends on $e$ and $I$ only, it is the same under all regimes. It remains to show that $t^{M}>t^{B}>t^{P}$. We confine attention to showing $t^{B}>t^{P}$, since the proof for $t^{M}>t^{B}$ proceeds analogously.

Without loss of generality, suppose $\underline{t}=0$. Plugging in the outcome from the bargain- 
ing game yields

$$
\begin{aligned}
& t^{B} \frac{(1-\beta)}{(1+\beta)}(h-\underline{e})+\left(1-t^{B}\right)(1-\beta) h \stackrel{!}{=} t^{P} \frac{(1-\beta)}{\mathfrak{q}^{1+\beta)}}(h-\underline{e})+\left(1-t^{P}\right)(1-\beta)\left(h-r^{P N}\right) \\
& \Leftrightarrow 0=\mathfrak{f}^{B}-t^{P^{\mathbf{x}^{\mu}}} \frac{(1-\beta)}{\boldsymbol{\mu}^{(1+\beta)}}(h-\underline{e})-(1-\beta) h+\left(1-t^{P}\right)(1-\beta) r^{P N} \Leftrightarrow \\
& \Leftrightarrow \quad 0={ }^{\mathrm{f}} t^{B}-t^{P \mathrm{a}^{\mu}} \frac{(1-\beta)}{(1+\beta)}(-\underline{e}-\beta h)+\left(1-t^{P}\right)(1-\beta) r^{P N} \Leftrightarrow \\
& \Leftrightarrow 0=\{\underbrace{\left.1-t^{P}\right)\left(z_{-\beta) r^{P N}}^{1-\mathfrak{f}^{B}}\right\}}_{>0}-t^{P^{\boldsymbol{\alpha}^{\mu}}} \frac{(1-\beta)}{(1+\beta)}(\underline{e}+\beta h)
\end{aligned}
$$

Since the first term of (19) is positive for all $r^{P N}>0$, the second must be positive as well. Since $\frac{(1-\beta)}{(1+\beta)}(\underline{e}+\beta h)>0$, this can only be true if $t^{B}-t^{P}>0$.

\section{F $\quad$ Proof of Proposition 2}

By Lemma $4, r^{P N}>\mathbf{e}$ implies that $u^{P, \max }<\boldsymbol{b}$. Thus, $\boldsymbol{b}$ is not feasible under regime $P$.

i) and iii) follow from the definition of $b$

ii) follows from $u^{P, \max }<\boldsymbol{b}$ and the fact that $e$ is increasing in $u$.

iv) Note first that we have $j s^{B}>j s^{P}$, since $j s^{l}$ is maximized at $t^{l}=\emptyset . I^{P}<I^{B}$ follows then immediately from the first order condition for $I^{l}, \frac{\partial p}{\partial I^{1}} j s^{l}=1$, which implies that $I^{l}$ is increasing in $j s^{l}$, given our assumptions on $p(I)$.

v) Overall surplus is uniquely determined by $I^{l}$ and $e^{l}$. Therefore, since $e^{B}>e^{P}$ and $I^{B}>I^{P}$, we have $S W^{P}<S W^{B}$.

vi) $t^{P}=\underline{t}$. Note that $J S$ is a concave function in $u$. Thus, for all $u<\boldsymbol{b}, J S$ is monotonically increasing in $u$, and $u$ is decreasing in $t$. Therefore, the smallest possible $t$ is chosen.

vii) From $\Pi_{h}^{l}=p\left(I^{l}\right) \cdot g\left(e^{l}\right) \cdot \pi_{h}^{l}(u)$ the statement follows immediately, given the results from parts i), ii), and iv), and using the fact that $\pi_{h}^{l}(u)=\frac{\beta}{(1-\beta)} u$ as derived in Lemma 3.

viiii) Since $\Pi_{i}^{l}=\Pi_{h}^{l}$ in equilibrium (see Lemma 2 ), from vii) we must have $\Pi_{i}^{P}<\Pi_{i}^{B}$.

\section{G Proof of Proposition 3}

By Lemma 4, $r^{M V}<\mathbf{e}$ implies $u^{M, m i n}>\boldsymbol{b}$. Thus, $\boldsymbol{b}$ is not feasible under regime $M$.

Parts (i) to (iv), as well as parts vii) and viii) follow from considerations analogously to the proof of Proposition 2.

v) $S W^{M} \lessgtr S W^{B}$ follows from the fact that $e^{M}>e^{B}$ but $I^{B}>I^{M}$. Which effect dominates depends on the parameters of the model.

vi) $t^{M}=1$. $J S^{M}$ is strictly decreasing in $u$ for all $u>b$. Thus, in order to decrease $u$, the longest possible contract is chosen, i.e. $t^{M}=1$. 


\section{References}

A c emog| u, D. (1997): "Training and Innovation in an Imperfect Labour Market," Review of Economic Studies, 64(3), 445-464.

A cemog| u, D., and J .-S. P ischke (1999a): "Beyond Becker: Training in Imperfect Labour Markets," Economic Journal, 109 (February), 112-142.

(1999b): "The structure of wages and investment in general training," Journal of Political Economy, 107(3), 539-72.

A nt onioni, P., and J. Cubbin (2000): "The Bosman ruling and the emergence of a single market in soccer talent," European Journal of Law and Economics, 9(2), 157173.

Burguet, R., R. Caminal, and C. M at ut es (2001): "Golden Cages for Showy Birds: Optimal Switching Costs in Labour Markets," European Economic Review, forthcoming.

D emset z, H . (1972): "When does the rule of liability matter?" Journal of Legal Studies, $1(1), 13-28$.

Feess, E., and G. Muehl heusser (2000): "The impact of the transfer fee system on wages, investment incentives and profits in professional football: the European Commission's New Suggestion," mimeo.

K esenne, S. (1999): "Player Market Regulation and Competitive Balance in a Win Maximizing Scenario," in Competition Policy in Professional Sports, ed. by S. K. C. Jeanrenaud, pp. 117-132. Neuchatel.

Quir k, J., and R. Fort (1997): Pay Dirt: The Business of Professional Sports. Princeton University Press, Princeton.

Spier, K ., and M. W hinst on (1995): "On the efficiency of privately stipulated damages for breach of contract: entry barriers, reliance, and renegotiation," RAND Journal of Economics, 26(2), 180-202.

Szymanski, T., and T. K uypers (1999): Winners and Losers: The Business Strategy of Football. Viking, London. 


\section{IZA Discussion Papers}

\begin{tabular}{|c|c|c|c|c|}
\hline No. & Author(s) & Title & Area & Date \\
\hline 408 & $\begin{array}{l}\text { H. N. Mocan } \\
\text { E. Tekin }\end{array}$ & $\begin{array}{l}\text { Nonprofit Sector and Part-Time Work: An } \\
\text { Analysis of Employer-Employee Matched Data } \\
\text { of Child Care Workers }\end{array}$ & 1 & $12 / 01$ \\
\hline 409 & $\begin{array}{l}\text { P. Apps } \\
\text { R. Rees }\end{array}$ & Fertility, Female Labor Supply and Public Policy & 6 & $12 / 01$ \\
\hline 410 & $\begin{array}{l}\text { H. Lehmann } \\
\text { J. Wadsworth }\end{array}$ & $\begin{array}{l}\text { Wage Arrears and the Distribution of Earnings in } \\
\text { Russia }\end{array}$ & 4 & $12 / 01$ \\
\hline 411 & S. Stillman & $\begin{array}{l}\text { The Response of Consumption in Russian } \\
\text { Households to Economic Shocks }\end{array}$ & 4 & $12 / 01$ \\
\hline 412 & $\begin{array}{l}\text { M. Barbie } \\
\text { M. Hagedorn } \\
\text { A. Kaul }\end{array}$ & $\begin{array}{l}\text { Government Debt as Insurance against } \\
\text { Macroeconomic Risk }\end{array}$ & 7 & $12 / 01$ \\
\hline 413 & $\begin{array}{l}\text { H. Bonin } \\
\text { R. Euwals }\end{array}$ & $\begin{array}{l}\text { Participation Behavior of East German Women } \\
\text { after German Unification }\end{array}$ & 1 & $12 / 01$ \\
\hline 414 & $\begin{array}{l}\text { A. Frederiksen } \\
\text { N. Westergaard- } \\
\text { Nielsen }\end{array}$ & Where Did They Go? & 1 & $01 / 02$ \\
\hline 415 & $\begin{array}{l}\text { M. Bertrand } \\
\text { F. Kramarz }\end{array}$ & $\begin{array}{l}\text { Does Entry Regulation Hinder Job Creation? } \\
\text { Evidence from the French Retail Industry }\end{array}$ & 6 & $01 / 02$ \\
\hline 416 & $\begin{array}{l}\text { B. Crépon } \\
\text { F. Kramarz }\end{array}$ & $\begin{array}{l}\text { Employed } 40 \text { Hours or Not-Employed 39: } \\
\text { Lessons from the } 1982 \text { Mandatory Reduction of } \\
\text { the Workweek }\end{array}$ & 6 & $01 / 02$ \\
\hline 417 & J. Wagner & $\begin{array}{l}\text { Taking a Second Chance: } \\
\text { Entrepreneurial Restarters in Germany }\end{array}$ & 1 & $01 / 02$ \\
\hline 418 & $\begin{array}{l}\text { M. Frölich } \\
\text { P. A. Puhani }\end{array}$ & $\begin{array}{l}\text { Immigration and Heterogeneous Labor in } \\
\text { Western Germany: A Labor Market } \\
\text { Classification Based on Nonparametric } \\
\text { Estimation }\end{array}$ & 2 & $01 / 02$ \\
\hline 419 & $\begin{array}{l}\text { P. Frijters } \\
\text { J. P. Haisken-DeNew } \\
\text { M. A. Shields }\end{array}$ & $\begin{array}{l}\text { The Value of Reunification in Germany: } \\
\text { An Analysis of Changes in Life Satisfaction }\end{array}$ & 6 & $01 / 02$ \\
\hline 420 & $\begin{array}{l}\text { Å. Rosén } \\
\text { E. Wasmer }\end{array}$ & $\begin{array}{l}\text { Higher Education Levels, Firms' Outside Options } \\
\text { and the Wage Structure }\end{array}$ & 1 & $01 / 02$ \\
\hline 421 & P. Manzini & Divide et Impera: Negotiating with a Stakeholder & 6 & $02 / 02$ \\
\hline 422 & $\begin{array}{l}\text { J. T. Addison } \\
\text { L. Bellmann } \\
\text { C. Schnabel } \\
\text { J. Wagner }\end{array}$ & $\begin{array}{l}\text { The Long Awaited Reform of the German Works } \\
\text { Constitution Act }\end{array}$ & 6 & $02 / 02$ \\
\hline 423 & $\begin{array}{l}\text { E. Feess } \\
\text { G. Muehlheusser }\end{array}$ & Transfer Fee Regulations in European Football & 1 & $02 / 02$ \\
\hline
\end{tabular}

